\title{
Politicisation or Professionalisation? Exploring Divergent Aims Within UK Voluntary Sector Peer Mentoring \\ Gillian Buck
}

\section{Abstract:}

Meaningful 'user involvement' is an established aim of social work practice, and increasingly, an aspiration of criminal justice, yet there are unique challenges to participatory work within punitive contexts. Drawing upon a study of peer mentoring in the voluntary sector, this article unveils some core tensions related to (ex)service user involvement in criminal justice. Interviews with mentors, mentees, and key stakeholders, along with direct observations of practice, reveal that respondents often see their work as personal-political, emphasising the value of lived expertise and of collective action to address limiting social conditions. Simultaneously, however, mentoring is framed nationally and shaped locally by more established aims to correct, improve, and manage, individual 'offenders'. There is, therefore, a fundamental tension between processes of politicisation, or coming together to assert a user voice and affect social change; and professionalisation, wherein mentors are co-opted into forms of practice they often critique.

Peer mentoring in criminal justice is an approach which draws upon the knowledge of people with lived experiences of crime and justice, to offer 'credible' inspiration and support to people in prison and community justice settings (see Buck 2017, 2018; Maruna 2017). While the roots of such 'mutual aid' have a long history (Maruna 2017), the approach has been bolstered in England and Wales in recent years by policy aims to employ (ex)'offenders' as 'wise friends' for people leaving prison (Grayling 2012). Indeed, this supportive 'through the gate' approach formed a central part of government plans to Transforming Rehabilitation (Ministry of Justice 2013). 
The recognition of the value of lived experiences in justice settings is not an isolated development, rather it forms part of an increasing emphasis on service user engagement in human services, given the necessity for methods that better suit service users' primary needs (Hughes 2012) and reduce the divisions between recipients and providers (Beresford 2016, p.310). Simultaneously there has been a political drive to develop volunteering in criminal justice (Cabinet Office 2010; Ministry of Justice 2008). In 2011, the National Offender Management Service (NOMS) awarded grant funding to eight voluntary and community sector organisations to form the NOMS volunteering and mentoring programme (Willoughby, Parker and Ali 2013). This constituted a strategic drive to increase the number of volunteer mentors for adults with convictions. Such a transfer of penal roles to community-level actors, Corcoran (2012) argues, 'is premised on a blend of neoliberal political rationalities for restructuring state welfare systems as "mixed service markets" in late capitalist societies and communitarian aspirations to liberate the untapped social capital of the community and voluntary sectors' (p.17, italics added). This curious mix of two different philosophies with overlapping interests is also present in the history of user involvement more broadly. For example, Beresford (2002) argues that 'two conceptual models to participation have predominated since the 1990's [ . . these are] "consumerist"' and "democratic" approaches' (p.96). The consumerist approach is concerned with improving welfare 'products' through 'consumer' feedback and consultation, whereas the democratic approach is concerned with people having more say in organisations which impact on them and more control over their own lives. While the consumerist approach emphasises 'efficiency, economy and effectiveness', the democratic approach foregrounds civil rights and collective action and is 'explicitly political' (Beresford 2002, p.97). Similarly, Cowden and Singh (2007) trace two opposing stories of the 'user movement': one story involves the success of service users gaining a voice in decision-making spaces, research and education; the other is a story of incorporation 
into a system 'driven by managerial, rather than democratizing imperatives', wherein service users are framed as consultants rather than activists (p.20). This article will explore the extent to which these different underpinning drivers can be traced in criminal justice contexts.

\section{The Research Study}

The data presented here are drawn from a qualitative, ethnographic study of four voluntary sector peer mentoring settings in the north of England. In an attempt to represent the lived experiences of those involved, a mixed methods approach was adopted, including 44 semi-structured interviews with key players (18 mentors, 20 mentees, four co-ordinators and two referring probation officers). Semi-structured interviews were employed to offer 'opportunity for dialogue and exchange between the interviewer and interviewee' (Noaks and Wincup 2004, p.79). Observations were also undertaken, including: volunteer recruitment days, mentor training courses, a volunteer supervision session, and peer mentoring groups.The approach was ethnographic, in that it balanced 'detailed documentation of events with insights into their meaning to those involved' (Fielding 2008, p.267). A purposive sampling method was adopted, as projects relevant to the topic were 'hand-picked' (Denscombe 2014, p.41) if they were operating in the voluntary sector and delivering peer mentoring in a criminal justice context. The final sample included: a peer-led service attached to a probation setting; a women's employment charity; a young women's 'gang' reduction programme, a care leavers' charity and three individual practitioners, who were each working in much smaller organisations or independently. The informed consent of all participants was sought and the purpose of the research, along with proposed uses of findings, made clear. Participation was voluntary and all respondents were informed orally and in writing that they had the right to withdraw completely or decline to answer (any) questions. Individuals and projects were anonymised in an attempt to encourage involvement (Maxfield and Babbie 2015, p.63) and offer protection to people and organisations. As there was a 
risk that interviews could reveal distressing memories, all participants were issued with a leaflet detailing local helplines and services. For a fuller discussion of ethical safeguarding strategies employed in the research see Buck (2016). All interviews were transcribed verbatim on a secured laptop, a process which was 'as much a form of interpretation and analysis as ... a technical activity' (Fraser 2004, p.188).

Observation data were recorded by hand contemporaneously in field diaries and later typed up. These diaries included separate sections, which recorded my own observations, impressions and comments. In order to analyse the amassed data, techniques of thematic analysis, critical discourse analysis and Gilligan's listening guide method were employed. Thematic analysis looks for themes in accumulated data, it 'involves making choices about what to include and implies some degree of repetition (King and Horrocks 2010, p.149). It is influenced by the grounded theory approach, which encourages researchers to remain 'open to the data' in order to 'discover subtle meanings and have new insights' (Charmaz 2014, p.137). Critical discourse analysis 'remains essentially a form of textual analysis. Typically it involves finding a regular pattern in a particular text or a set of texts ... and then proposing an interpretation of the pattern, an account of its meaning and ideological significance' (Cameron 2001, p.137). While this technique is useful for highlighting unspoken dynamics, there are concerns that it positions the analyst as superior to the speaker and implies that with the correct analytical process, a critical version of truth superior to the speakers can be gotten at (see Stanley andWise, 1993, p.15). In an attempt to address this imbalance, elements of Gilligan's 'voice method' or 'listening guide' were also employed (Kiegelmann 2009). This method attempts to include a fuller representation of the researcher's position in the analysis. Gilligan suggests, for example, that analysts identify their own responses to data, so that objectivity 'becomes a matter not of avoiding relationship but paying attention to relationship, not silencing yourself but distinguishing your voice from that of the other person' (Kiegelmann 2009, p.39). In order to ensure this reflective approach did not lose sight of respondent perspectives, events were arranged to present preliminary analyses 
and 'member check' emerging findings (Rubin and Babbie 2012). One of the unexpected themes that emerged from the analysis of data, was how those involved with peer mentoring often become politicised.

\section{Theorising Peer Mentoring as Political}

Peer mentoring can be theorised as a form of politicisation, given that it permits a voice of experience, which has long been 'silenced, subjugated or disqualified ... [as] prisoners' version of "the truth" is located at the bottom of the hierarchy of knowledge' (Ballinger 2011, p.110). It also works 'beyond . . the cognitive deficitmodel to harness the strengths residing in peer support networks' (Weaver 2012, p.407).However, this radical potential coexists with a focus which remains upon 'offenders' as recipients, as subjects who require improvement with the help of morally superior others. It therefore sustains the corrective, normative ethos, which is already dominant in criminal justice. The work of seminal critical educator, Paulo Freire, is helpful for theorising this tension. Freire (1996[1970]) explored how teaching conveys unacknowledged power relations and advocated that we abandon 'the educational goal of deposit making and replace it with the posing of the problems of human beings in their relations with the world' (p.60). This, indeed, appears to be one of the premises of peer mentoring. Kram and Isabella (1985), for example, suggest that peer relationships are unique because they offer a degree of mutuality that enables both individuals to experience being the giver and receiver of key functions (cited by Ensher, Thomas and Murphy 2001, p.423), the sense of mutuality or egalitarianism possible through peer-to-peer work has the potential to 'reconcile the poles of the contradiction so that both are simultaneously teachers and students' (Freire 1996[1970], p.53). Little has previously been written about the political action of criminalised people. Where reference is made, it is in the context of broader campaigns of resistance, such as those of political prisoners (Corcoran 2013), or in terms of 'disturbance', rather than positively organised challenge. 
Martinson (1972, p.3), for example, refers to rioting as an attempt to improve conditions from within, and to 'expressive mutiny [which] aims to communicate the inmates' plight to the public so far as he understands it'. Bosworth and Carrabine (2001) note that terminology, such as 'disturbance, disorder or riot' which frame acts of resistance, has political connotations - 'deployed by the Right to conjure up images of pathological and dangerous individuals', similarly the terms preferred by the Left, such as 'rebellion, protest and resistance' are hardly neutral (p.506). Their nuanced analysis illustrates that power in prison is constantly contested, and that while subversive actions are structured in part by identity, by the available scripts of gender, ethnicity, class and sexuality, 'prisons may be altered from the inside out by those very individuals who are subject to its control' (p.513). There are also some implied references to politicisation within the peer mentoring literature, in both prison and community locales. Kavanagh and Borrill (2013, p.403) for example, have recognised that mentoring can be 'empowering in both prison and probation settings' in contrast to previous experiences of feeling 'powerless'. Similarly, Pollack (2004) argues that peer support services can be liberatory for women in prison: The fact that the group was co-facilitated by prisoners, rather than by professional staff, greatly enhanced a sense of self-reliance and the autonomy of prisoner participants who have so few opportunities to author their own stories and define their own needs. (p.703). Peer mentoring here, emerges as a stylistic rebellion to the stigma and exclusion that 'offenders' often experience. It is an activity which politically turns the power of these exclusions on their head. Past experiences of offending are transformed from a limitation into a unique resource.

More recently, Maruna (2017, p.11) has gone so far as to trace the seeds of a 'desistance movement', wherein groups of (ex)prisoners organise to challenge stigma and discrimination and assert their own voice. Pointing to social movements in the fields of mental health and addiction recovery, which have seen stigmatised groups organise for their rights and reject pathologising treatments in favour of 
mutual-aid recovery communities, he goes on to argue: 'I see this as an inevitable next step on the journey for the desistance idea, as that concept moves from the Ivory Tower to the professional world of probation and prisons, back to the communities where desistance takes place' (pp.10-11). There are, however, barriers to these techniques of inversion, as foretold by philosopher Mikhail Bakhtin's (1984[1965]) analysis of the ultimate stylistic rebellion - the medieval carnival.

Bakhtin saw the carnival as 'temporary liberation from the prevailing truth and the established order; it marked the suspension of all hierarchical rank, privileges, norms, and prohibitions' (p.10). This is redolent of peer mentoring, in that (ex)'offenders' enter spaces and roles that were previously open only to professional officers. In both prison and probation settings this results in more free and familiar contact 'between people who would usually be separated hierarchically' (Vice 1997, p.152). The carnival also conjures images of celebration, newness and subversion, much like "'Mentoring moments" [which are said to provide] the opportunity to think new thoughts and realize a new future' (Brown and Ross 2010, p.35). However, carnivalesque events are not revolutionary, rather they are 'grudgingly accepted' while being 'heavily policed and contained' (Sibley 1995, p.44). This also rings true of mentors with convictions, who are granted a role in criminal justice, but only as a heavily-managed subpractice within a more punitive overriding framework. Peer mentors in prison settings, for example, are often only granted access subject to additional supervision and scrutiny (Buck 2014). In this light, peer mentoring becomes a 'carnival' of borrowed control, which ultimately remains heavily contained. Indeed, Sibley (1995, p.46) argues that such limited inclusion may serve only to highlight marginality: 'the oppressed have their own strategies which challenge the domination of space by the majority, if only briefly and in prescribed locales. Ultimately, carnivalesque events confirm their subordination'. While peer mentoring may constitute a challenge to the domination of the justice space by professional 'experts', therefore, it remains embedded within a wider disciplinary system, which is managerial and hierarchical. Indeed, while criminal justice regimes 
'differ from place to place, just as the ground beneath us is uneven and quietly moving' (Goodman, Page and Phelps 2017, p.15), there are tangible barriers to delivering interventions based upon mutual trust within 'coercive and punitive criminal justice system preoccupied with concerns about risk' (Hucklesby and Wincup 2014, p.379). These tensions will now be explored.

\section{Findings: Peer Mentoring as Politicisation}

Many of the mentors and mentees who spoke to this study saw their work as a personal-political practice, grounded in reflections upon 'relations with the world' (Freire 1996[1970], p.60). Julie,1 for example, feels she has a good understanding of the criminal justice system because:

I've been there myself. Also other things in my past, like getting in trouble, having horrible ex-boyfriends, other things have happened to me and I think I use that knowledge to guide them. (Julie, mentor)

Lin valued such grounded guidance:

It's somebody that's had a similar experience or similar problem to me, but found a way to overcome it and then they would guide their peer by their own experiences. (Lin, mentor and previously a mentee)

However, speakers do not just highlight the importance of personal experience, they also often create a hierarchy of knowledge. Lived experiences are elevated above learned, professional knowledge:

Someone who could have been brought up with a silver spoon in their mouth, and gone through college and university, and five minutes out of university, have to get a map out to find where you are and want to sit and tell you how 
to deal with your life and cope with things. Well, no, 'go away I'm not listening to you!' With a peer it's equal, it's on the same level. (Katy, mentor)

Some of them [probation staff] just don't know what they're talking about, who've not been there. Alright they might have read it in books, but you're not going to know unless you've been there and done it, in my eyes anyway. (Don, mentee)

There is an emotive othering of knowledge sources taking place, whereby 'books' and formal learning are relegated in favour of the sensed, the felt, the experienced. Indeed, there is also an othering of the people who rely upon such formal knowledge. These speakers caricaturise officials by inverting the props and associations of professionalism, or more accurately of social superiority. Peers who have 'been there' are elevated above people (particularly professionals) who they assume have not. The peer mentor identity is therefore formed, in part, through the threat and 'practice of exclusion' (Spalek 2008, p.13). However, this exclusion is targeted, it challenges the established order and dominant definitions of expertise.

Underlying this narrative is a 'spirit of carnival ... the symbolic destruction of authority and official culture and the assertion of popular renewal' (Arnds 2008, p.70). The rhetorical inversion of expertise signifiers is an attempt to undermine established approaches to 'rehabilitation', which have been experienced as excluding. A necessary precursor to the symbolic destruction of professional status is the establishment of a common contrary position, one from which alternative truths, action and shared purpose can emerge. All of the respondents cited above (and indeed many other speakers in the study) construct an 'expert ex-offender' identity. While perhaps not consciously so, this constitutes political action in itself. Identifying with others through the construction of shared identities constitutes what hooks (1994) terms 'identity politics', which emerge, she argues: 'out of the 
struggles of oppressed or exploited groups to have a standpoint on which to critique dominant structures, a position that gives purpose and meaning to struggle' (p.89). Peer mentoring, in this light, can be understood as a form of consciousnessraising, a means for challenging oppression in solidarity with others who identify the same way (Gilchrist, Bowles and Wetherell 2010, p.22). Claiming shared identity allows people to enjoy positive affirmation of their experience, contribute to collective action and may open up new insights into how to gain opportunities in an unfair world (p.22), this creates new possibilities for the practice; not just as an interpersonal exchange, but as part of a larger 'social movement' of reformed offenders (Maruna 2017, p.13).

The political potential of peer mentoring is furthered by the fact that spoken challenges to expert knowledge are often accompanied by broader consciousnessraising activities. Indeed, each of the projects in this study were engaged in some form of consciousness-raising activity. Some had published their own academic or newspaper articles, promoting the value of personal experience when helping others. Some spoke at, or organised, conferences to highlight the lived experience of particular groups, while others took action to challenge existing perspectives or exclusions. Lol, for example, is a mentoring co-ordinator who describes himself as an 'ex offender' and a 'care leaver', given that he was taken into the care of the local authority as a child and later spent time incarcerated. He now works for a charity which is trying to understand why somany children who grew up in 'care', go on to be imprisoned. This is an issue he feels is neglected by criminal justice providers:

$25 \%$ plus of those in prisons can say they've been in care. You can't just take people from the care system and say 'they are bad people so they end up there'. There must be something happening, systemic. So we're trying to work out, our project is about trying to work out, where those gaps exist in terms of that system. (Lol, mentoring co-ordinator) 
Keisha, who spent a number of years in prison herself and struggled to find employment with a criminal record, is working to challenge this exclusion:

We are working on workshops for employers to take on ex-offenders, using family member videos. Like a woman whose husband's got a criminal record; his record's going to be discussed and how he got into it and then the wife is going to plead to this employer why it's so important for them to give her husband a chance ... We're going to do a campaign, I can fight for the people like me and there is quite a few of us. (Keisha, peer mentor)

Many mentors and co-ordinators, therefore, behave as public advocates, promoting the integration and acceptance of criminalised people, who they currently see as excluded or misrepresented. Their aims are to establish new understandings, to secure more effective resources or services, and to challenge discrimination.

\section{Professionalisation in Mentoring}

While there are traces of politicisation within peer mentoring, of people coming together to assert a voice and to challenge expert knowledge and divisions, there was also evidence of peer mentors being co-opted into 'expert' approaches, of mentors themselves being moulded into 'professionals'. This process had four identifiable elements: selection; training; supervision; and regulatory professionals.

\section{Selection}

During the fieldwork phase of this study, I was permitted to observe a round of interview and selection processes for prospective volunteer peer mentors at one project. The interviews were conducted by the project's two co-ordinators (Adam and Cam) who had histories of repeat imprisonment and substance addiction respectively, and their manager, a local probation service supervisor. Adam took the lead for the most part, explaining to interviewees the informality of the process. 
Despite this statement, however, discussions maintained much of the familiar performance of a structured job interview. Interviewees sat opposite the panel of three and were asked a series of predetermined questions. After each interview, the panel discussed the merits of the candidate. It was during these discussions that the power of recruiters to select a particular type of 'offender voice' became apparent. In fact, rather than focusing on the range of personal experiences that volunteers were bringing to the post, the panel focused on volunteers' understanding of 'boundaries', of the mentoring role and of 'inter-agency working'. Where they had reservations, it was often on the grounds of candidates still being 'at the client point of view', or if they were concerned about a candidate's ability to understand 'theories' or complete 'star charts'. The 'star chart' referred to here is an Outcomes StarTM, developed by a consulting firm 'for ... measuring change when working with people' (Triangle Consulting Social Enterprise 2018). Mentees score each area of their life on a scale of 1-10 in order to identify areas for improvement. The process is then repeated at regular intervals to track progress. The mentee, therefore, is very clearly categorised in terms of the changes they need to make, and made aware from the outset that their progress will be monitored. While this tool does acknowledge social factors (for example, friends and community), it encourages the mentee to individualise problems in these areas and become personally responsible for addressing them. By recruiting on the basis of suitability for approaches such as this, services recruit in terms of how well applicants could fit into existing knowledge streams and processes, which had - up to that point - been heavily influenced by the probation service. This is not so much creating a space for peer knowledge and understanding, nor a standpoint that 'gives access to understanding about oppression that others cannot have' (Stanley and Wise 1993, p.91), but rather is a form of semiprofessionalisation. In Bakhtinian terms, this 'peer' provider misses the opportunity to seek liberation from the established order, by validating existing practices: 'where carnival satirizes extant power structures, it does so by mimicry, thus finally validating the potency of the hierarchy' (Presdee 2000, p.41). 


\section{Training}

Not only were volunteers often carefully selected on the grounds of their ability to fit with institutional norms, but they were also formally trained for the role:

The best thing is ... getting training. Like my NVQ Level 3 [Health and Social Care Qualification], I wouldn't have gone to college for that . . No-one has ever like tried to help me like that. I mean, yeah: 'go to college', but I'm unconfident going to college, so now a tutor comes here [to the mentoring project] to see me. (Julie, mentor)

Like Julie, mentors from across the projects spoke of appreciating the opportunity to complete a Health and Social Care National Vocational Qualification (NVQ). This qualification is designed to 'equip learners with the skills and knowledge needed to care for others in a broad range of health or social care settings' (City and Guilds 2018). Courses impart ideal typical working practices such as: effective communication; health, safety and security; reflective practice and the protection of children (City and Guilds 2018). Peer mentors are, therefore, given very clear instruction on the type of worker to become, a becoming which requires that they see themselves as facilitators of change, see quasi-therapeutic methods and techniques as the conduits of change and see their mentees as in need of improvement. The power to define peer mentoring in practice, then, comes from an established frame of existing professional and pedagogical knowledge, as opposed to a previouslyexcluded voice of experience. It is important to note, however, that such formal education offers volunteers a valuable sense of validation:

It never even crossed my mind to come to University [which Ellie went on to post mentoring], and then ... I found [mentoring project], did an interview, 
did their training, and became one of their first peer mentors, that's when I really formulated my ideas of what a peer mentor is. (Ellie, mentor)

Such opportunities appear to 'empower' mentors who have previously felt disempowered. They enable people like Ellie and Julie to gain skills and pursue careers they had not thought possible and to feel valued. The trade-off, however, is that such opportunities constitute something different from an ex-offender standpoint epistemology; to peers forming 'solidarastic groups' to protect themselves (Pawson 2004, p.52) against a system which deconstructs the subjective experiences of crime and change. In other words, while such structured training appears to offer individual validation and professional credibility, it also endorses normative educational and professional conformity. These programmes do not always prioritise the 'ex-offender' voice or lived experience, but, instead, can rely heavily upon pedagogical frameworks borrowed from the fields of coaching, guidance, and social care. They turn peer mentoring 'students' into 'containers', into 'receptacles' to be 'filled' by knowledgeable teachers (Freire 1996/[970], p.53). In addition to 'formal' training, the majority of projects prescribed specific mentoring approaches. Two projects, for example, required volunteers to attend compulsory two- or three-day training courses, which focused upon ideal-typical ethics and practices. Topics on the first course included: mentoring as a teaching and guiding tool; communication and boundaries; trust building; conflict management and confidentiality; and 'mentoring in practice', which focused on multi-agency working, advocacy, goal setting and the need for volunteer supervision. Topics at the second course included: information, advice and guidance; listening skills; ways to empower and enable (including encouraging self-reliance); boundary setting; equality; and coping with 'difficult situations'. Most of this training drew upon professional norms, yet worked hard to incorporate a 'user voice'. At one project, for example, the trainers heavily promoted the importance of the mentee directing the relationship, and mentors drawing upon their own experiences: 
Have a friendly chat, see where they're [mentee] at. It's different to 'assessments'; what professionals see as important ... Relate back to being an offender yourself - remember what it was like to feel rejected. (mentoring coordinator and trainer)

Mentoring is about your character and sincerity.We provide the skills, but it's about you. (mentoring co-ordinator and trainer)

These ideals were supported by role play activities in which trainees were encouraged to practice listening without 'advising', which 'is a block to listening' (trainer) and to not 'project your issues, stick with [mentee] aims' (trainer). However, the training also promoted practices which constituted well-established probation approaches. These included setting 'achievable' goals, improving individual skills and reporting concerns back into formal risk assessments:

Use the goal setting form. Goals must be SMART. This means specific, measurable, achievable, realistic, time bound. (trainer) Social skills are key. For example, shopping, cooking skills, the life skills group ... 'Life skills' - helping to get them ready for work and education. (trainer)

Any concerns [such as mentees not attending mentoring or being involved in crime] should be fed back to the Offender Manager. (trainer)

Similarly, while mentors at one project were advised to 'suspend [their] own concerns' and not speak over people, they were also reminded that: 'employment is our overall aim' and that there should be: 'No home visits, no child minding. Don't introduce your friends and family. No personal numbers, it is not a friendship. No personal details, if asked keep it light. No Facebook. No gifts from clients' (peer mentor trainer). Both of these training courses therefore included efforts to 
professionalise peer mentors. Such efforts offer mentors and their agencies a sense of safety and credibility, but they equally risk submerging any new knowledge or ways of working in established practices. The hazard in such a prescribed context is that 'user voices' become tokenistic. Moreover, there is the danger of co-option to the very system which peer mentoring often critiques. On a broader scale,Garland (2002) argues that we have seen a 'responsibilization strategy' in crime control in recent years. This strategy seeks to enlist the 'governmental' powers of private actors and 'spread responsibility for crime control onto agencies, organisations and individuals that operate outside the criminal justice state and to persuade them to act appropriately' (Garland 2002, p.124). Training the providers of purportedly 'peer led' services in ways to 'act appropriately' appears to illustrate this strategy in action. Garland (2002) also argues that in the 'new culture of crime control': The offenders dealt with by probation, parole and the juvenile court are now less likely to be represented in official discourse as socially deprived citizens in need of support. They are depicted instead as culpable, undeserving and somewhat dangerous individuals who must be carefully controlled for the protection of the public and the prevention of further offending. (p.175) These opposing constructions represent a conflict that is persistently present in peer mentoring. In justifications for their practice, mentors repeatedly describe their peers as deprived citizens in need of support, yet they necessarily operate within a system which characterises 'offenders' as actual and potential risks. By adopting tools that have been developed to manage culpable and dangerous offenders, therefore, these 'semi-professionalised' mentors risk compromising their own welfare philosophy. One project, in intention at least, offered a model to resist such capture. The co-ordinator of this project chose not to base volunteer training upon standardised social care strategies, but upon what potential mentors and mentees themselves deemed to be priorities. In an attempt to facilitate this, the project hosted 'consultation groups' in both prison and community settings with people who had previous convictions and a history of living in local authority care: 
The consultation process was about understanding, from the potential mentors and mentees, what would attract you to it ... we talk about where support would need to be if mentoring was to work. (Lol, mentoring coordinator)

The intention of the project founders was that training not be imposed upon mentors as 'banking' of known knowledge, but developed in consultation. This process is closer to the 'libertarian' form of education, advocated by Freire, which reconciles the teacher-student contradiction, 'so that both are simultaneously teachers and students' (Freire 1996[1970], p.53). The method prioritises an 'ex-offender' voice above established pedagogical knowledge and frameworks. Unfortunately, this alternative training approach was not embedded before the end of the research period. It would, therefore, be interesting to follow up such ideals in practice; to see if projects are able to achieve collaborative aims, and to analyse if any different forms of learning result.

\section{Supervision}

We do have formal supervision about once a month. (John, mentor) Another feature of subtle influence within peer mentoring is the formal 'supervision' of volunteers. In most settings this resembled social work supervision, wherein: ' $\mathrm{t}$ ] he supervisor is in indirect contact with the client through the worker [helping ... ] the direct service worker to help the client' (Kadushin and Harkness 2014, p.10). Supervision is, therefore, an indirect, but vital process, which is also 'administratively oriented ... to ensure quality of service to clients' (Tsui 2004, p.9). In most of the mentoring settings observed, mentors are not only carefully selected (in many cases by their ability to fit with an institutional culture) and trained in how to mentor, but most mentors are also formally supervised by managers or coordinators, offering further organisational power over the development of the mentoring relationship. At all of 
the participating projects, volunteers met with a supervisor or co-ordinator monthly or bimonthly to discuss the progress of cases and seek guidance and support. I had the opportunity of observing one of these supervision sessions between a peer mentor and his manager:

Supervisor:What do you still think needs to be done? [With mentee being discussed]

Peer mentor: He definitely needs handing over [to a partner agency]. I've discussed this with him in depth.

Supervisor: I'd agree, just have a conversation with him and the worker; let them know you're moving on, that [we are] always available. Also do an Outcome Star [assessment] ASAP and this will be used to avoid duplication.

This particular mentor also sought advice on how his practice could be improved, what he could 'do better':

Supervisor: Take risks talking to people, get to know the paperwork, prep beforehand so you're not always relying on the mentee to come up with the solution.

This exchange suggests that there is a displacement of informal mentoring with more disciplined activity and that some of the decision making, which appears to take place within the mentoring relationship, may actually happen in supervisory spaces such as these. It is here that the work is given formal shape and informal influence, where tools are offered and tactics suggested.

\section{Professional Regulation}

Finally, in addition to the visible (if not fully acknowledged) structuring activities of selection, training, and supervision, there was some evidence of attempts at 
professional regulation from beyond the parameters of mentoring settings. On one occasion, for example, I attended a conference organised by a female mentoring project, aimed at raising awareness of the needs of women in the criminal justice system. Part of the conference included a 'workshop' facilitated by two young peer mentors with 'experience of serious youth violence'. The workshop discussion focused on risk factors for young women who may be drawn into 'gang activity' and predominantly on young women at risk of exploitation by male gangs. At one point in this discussion, one of the facilitators, a young, black, female mentor, used the workshop to question the intersection of race and class in her own experiences with the police:

Why do police have conviction rates? Crime is crime. They gave us our name as a gang, put cameras on us, we start walking like that, together as a group, 'cos it's well-lit and we feel safe. On the street with my urban friends I was stopped all the time, when I went to University, in the same numbers I was not stopped. (Hope, mentor)

This was one of the few times during the study that I heard a mentor (as opposed to a co-ordinator) being critical of the social order, that I heard a mentor critically question the structural influences upon her life. This may well be because, as illustrated above, the approaches and beliefs of mentors are subject to much formal filtering and shaping. What was particularly interesting about Hope's insights here, however, was the response they received. At the end of the workshop, Hope's manager asked a probation officer (who had been in the workshop) how the 'girls had done'. The officer's response was that it was 'great' but that 'they need to rein in their personal opinions a bit'. This assumption that mentors should collude with the established knowledge of professionals constituted an attempt to silence Hope's voice of experience. It also evoked the arguments of 'Angela Y. Davis (1981) and Patricia Hill Collins (2000) [who] discuss subordinating images of black women [ . . 
including] "Uppity" black women [who] do not "know their place" and expect to be treated as though they were equal to white women or to white men' (Martin and Jurik 2006, p.44). While the officer's comment here did not appear to be consciously about undermining Hope on the grounds of her race or gender, it, nonetheless, communicated that Hope's personal opinions (or experiences) are in need of external moderation; that she should not expect her own voice to have prominence.

Regardless ofHope being offered a platform, therefore, in actuality, as a young, black, female, peer mentor she is relegated to a denizen or 'subaltern' voice (Spivak 1988). Her marginalised voice is dismissed as 'personal' by the dominant speaker before it is fully heard. In this moment, a 'user voice' is invited to join the justicepractice conversation, but is also expected to perform a marginalised status and endorse established rhetoric. The risk here is that (ex)offenders may play a part in the justice system, but only if they are suitably grateful and conformist.

\section{Peer Mentoring as it Could be: Beyond the Carnival}

Tomczak (2014, p.482) highlights how important it is for theorists of the penal voluntary sector to 'envision alternative possibilities and counter movements to neoliberal penal reforms and penal expansionism'. Recognising new (and possible) organisationalmodels, offers both a fuller account of the voluntary sector in criminal justice and helps to 'check the criminological propensity towards dystopia' (Tomczak 2014, p.483). For peer mentoring to move beyond 'carnivalesque' symbolism, beyond temporary and partial liberation from established regimes of discipline, we need to pay attention to how subordination and abjection are experienced and resisted (Tyler 2013). One aspect of resistance that has been traced here is the offer of alternative (lived) narratives to frame, and respond to, the experience of criminalised people, indeed it is argued that:

[I]f we want to achieve the kind of 'justice' which fosters egalitarian relationships between individuals, groups and communities, then we must 
include informal, marginal, subaltern and subversive discourses. (Campbell 2011, p.168)

Hearing (and including) these voices, however, may require openness to challenging dominant professional discourses and practices. A second way that mentors with convictions begin to raise themselves as a population is to come together, to find solidarity with 'folks like themselves' (hooks 1993, p.77). These may be other folks with convictions, or of the same gender (see Rumgay 2004), or broader/multiple connection points. Indeed 'identity politics based on an essentialist singling out of just one of [a human subject's multiple identities ... ] will not successfully empower individuals. Rather, we will require many networks and coalitions, membership in many oppositional communities' (Ferguson 1996, pp.122-3). While speaking collectively from one identity position may be momentarily empowering, and, indeed, may offer a vehicle for establishing previously unacknowledged perspectives, it neglects the multiplicity of human subjectivity. It relies upon a degree of conformity to a singular identity and of identical experiences within that identity. The way out of this dilemma, Ferguson (1996) suggests, is to acknowledge that identity is multifarious (intersectional) and that subjects will require many networks with which to identify. In the context ofmentoring, this implies the importance of people with lived experiences of crime and desistance collaborating to establish shared (counter) narratives, and of recognising the diversity of experiences among people who come to mentoring from different social locations.

\section{Conclusion}

In conclusion, it appears that peer mentoring can provide a platform for previouslysubmerged voices, position people in new ways and ask questions of established approaches. In this sense it is often a critical and political practice, which has potential to foster egalitarian relationships and include marginal or subaltern voices. Such levelling may enhance learning on all sides, opening spaces for alternative understandings and solutions. On the other hand, however, much like Bakhtin's 
carnival, peer mentoring is a sanctioned and very much contained practice. It may well express revolutionary ideals to undermine 'expert' knowledge and change stigmatising and excluding social practices, but it does so within a form that is governed by professional norms. Volunteers do not always distribute their knowledge on a free stage, but can have their knowledge selected (through recruitment processes), restricted and shaped in professionally palatable ways (through training), and monitored and contained (through supervision). Furthermore, the audiences which are exposed to lived experiences are often firmly embedded in the rational choice, authoritarian discourse of existing justice systems. Peer mentoring in this light is less radical, it allows people a voice, but only insofar as they perform as cheaper (often unpaid) professional justice staff, and, indeed, adopt many of the same approaches. Not a revolution then, but the testing of personnel margins and divisions on safe ground. Limited inclusion is permitted here, but it is also contained. In imagining peer mentoring beyond this bind, this article calls for mentors and providers to recognise and build upon the ethicopolitical nature of their task - to not ignore, but embrace the (often challenging) messages inherent in lived narratives of crime, and to work in solidarity with others with lived experiences to advance submerged forms of knowledge. The efforts highlighted here indicate that doing these things may shift the focus of criminal justice toward the need for social change in addition to individual change.

\section{Notes}

1 All names of respondents are pseudonyms. 


\section{References}

Arnds, P. (2008) 'Blasphemy and sacrilege in the novel of magic realism: Grass, Bulkakov and Rushdie', in: E.B. Coleman and M.S.F. Dias (Eds.), Negotiating the Sacred II: Blasphemy and Sacrilege in the Arts, Canberra, Australia: ANU E Press.

Bakhtin, M. (1984[1965]) Rabelais and his World, vol. 341 (reprint), Bloomington, IN.: Indiana University Press.

Ballinger, A. (2011) 'Feminist research, state power and executed women: the case of Louise Calvert', in: S. Farrall, R. Sparks and S. Maruna (Eds.), Escape Routes: Contemporary Perspectives on Life after Punishment, Abingdon: Routledge.

Beresford, P. (2002) 'User involvement in research and evaluation: liberation or regulation?', Social Policy and Society, 1(2), 95-105.

Beresford, P. (2016) All our Welfare: Towards Participatory Social Policy, Bristol: Policy Press.

Bosworth, M. and Carrabine, E. (2001) 'Reassessing resistance: race, gender and sexuality in prison', Punishment $\mathcal{E}$ Society, 3(4), 501-15.

Brown, M. and Ross, S. (2010) 'Mentoring, social capital and desistance: a study of women released from prison', Australian \& New Zealand Journal of Criminology (Australian Academic Press), 43(1), 31-50.

Buck, G. (2014) 'Civic re-engagements amongst former prisoners', Prison Service Journal, No. 214, 52-7.

Buck, G. (2016) 'Peer mentoring and the role of the voluntary sector in [re]producing "desistance": identity, agency, values, change and power' (PhD thesis, Keele University, unpublished).

Buck, G. (2017) "“I wanted to feel the way they did": mimesis as a situational dynamic of peer mentoring by ex-offenders', Deviant Behavior, 38(9), 1027-41.

Buck, G. (2018) 'The core conditions of peer mentoring', Criminology E Criminal Justice, 18(2), 190-206.

Cabinet Office (2010) The Role of Third Sector Innovation: Personalisation of Health and Social Care and Services to Reduce Re-offending, London: HM Government.

Cameron, D. (2001) Working with Spoken Discourse, London: Sage.

Campbell, E. (2011) 'The cultural politics of justice: Bakhtin, stand-up comedy and post-9/11 securitization', Theoretical Criminology, 15(2), 159-77.

Charmaz, K. (2014) Constructing Grounded Theory, 2nd edn, London: Sage.

City and Guilds, (2018) 'Health and Social Care' Qualification Outline. Available at: http://www.cityandguilds.com/qualifications-and-apprenticeships/healthandsocial- care/care/4222-health-and-social-care\#tab=information\&acc=level2 (accessed 1 July 2018).

Corcoran, M. (2012) "Be careful what you ask for": findings from the seminar series on the "Third sector in criminal justice", Prison Service Journal, No. 24, 17-22. Corcoran, M. (2013) Out of Order, Cullompton: Willan. 
Cowden, S. and Singh, G. (2007) 'The "user": friend, foe or fetish?: a critical exploration of user involvement in health and social care', Critical Social Policy, 27(1), 5-23.

Denscombe, M. (2014) The Good Research Guide: For Small-scale Social Research Projects, $4^{\text {th }}$ edn, Maidenhead: McGraw-Hill Education (UK).

Ensher, E.A., Thomas, C. and Murphy, S.E. (2001) 'Comparison of traditional, stepahead, and peer mentoring on prot'eg'es' support, satisfaction, and perceptions of career success: a social exchange perspective', Journal of Business and Psychology, 15(3), 419-38.

Ferguson, A. (1996) 'Can I choose who I am? And how would that empower me? Gender, race, identities and the self', in: A. Garry and M. Pearsall (Eds.), Women, Knowledge and Reality: Explorations in Feminist Philosophy, 2nd edn, London: Routledge.

Fielding, N. (2008) 'Ethnography', in: G.N. Gilbert (Ed.), Researching Social Life, 3rd edn, Los Angeles, CA.: Sage.

Fraser, H. (2004) ‘Doing narrative research analysing personal stories line by line', Qualitative Social Work, 3(2), 179-201.

Freire, P. (1996[1970]) Pedagogy of the Oppressed (reprint), Harmondsworth: Penguin.

Garland, D. (2002) The Culture of Control: Crime and Social Order in Contemporary Society, Oxford: Oxford University Press.

Gilchrist, A., Bowles, M. and Wetherell, M. (2010) Identities and Social Action: Connecting Communities for a Change, London: Community Development Foundation.

Goodman, P., Page, J. and Phelps, M. (2017) Breaking the Pendulum: The Long Struggle over Criminal Justice, Oxford: Oxford University Press.

Grayling, C. (2012) Justice Minister's 'Rehabilitation Revolution' Speech, 20 November. Available at: http://www.justice.gov.uk/news/speeches/chris-grayling/speechto-the-centreof-social-justice (accessed 1 January 2016).

hooks, b. (1993) Sisters of the Yam: Black Women and Self-recovery, London: Turnaround.

hooks, b. (1994) Teaching to Transgress: Education as the Practice of Freedom, New York: Routledge.

Hucklesby, A. and Wincup, E. (2014) 'Assistance, support and monitoring? The paradoxes ofmentoring adults in the criminal justice system', Journal of Social Policy, 43(2), 373-90.

Hughes, W. (2012) 'Promoting offender engagement and compliance in sentence planning: practitioner and service user perspectives in Hertfordshire', Probation Journal, 59(1), 49-65.

Kadushin, A. and Harkness, D. (2014) Supervision in Social Work, 5th edn, New York: Columbia University Press.

Kavanagh, L. and Borrill, J. (2013) 'Exploring the experiences of ex-offender mentors', Probation Journal, 60(4), 400-14. 
Kiegelmann, M. (2009) 'Making oneself vulnerable to discovery: Carol Gilligan in conversation with Mechthild Kiegelmann', Forum: Qualitative Sozialforschung [Forum: Qualitative Social Research], 10(2). Available at:

http://www.qualitativeresearch.net/index.php/fqs/article/view/1178/2719 (accessed 10 December 2018).

King, N. and Horrocks, C. (2010) Interviews in Qualitative Research, Los Angeles, LA.: Sage.

Kram, K.E. and Isabella, L.A. (1985) 'Mentoring alternatives: the role of peer relationships in career development', Academy of Management Journal, 28(1), 110-32.

Martin, S.E. and Jurik, N.C. (2006) Doing Justice, Doing Gender: Women in Legal and Criminal Justice Occupations, London: Sage.

Martinson, R. (1972) 'Collective behavior at Attica', Federal Probation, 36(3), 3-7.

Maruna, S. (2017) 'Desistance as a social movement', Irish Probation Journal, 14(1), 516.

Maxfield, M. and Babbie, E. (2015) Research Methods for Criminal Justice and Criminology, 7th edn, Stamford, CT.: Cengage Learning.

Ministry of Justice (2008) Third Sector Strategy: Improving Policies and Securing Better Public Services through Effective Partnerships 2008-2011, London: HM Government.

Ministry of Justice (2013) Transforming Rehabilitation: A Strategy for Reform, London:HM Government.

Noaks, L. andWincup, E. (2004) Criminological Research:Understanding Qualitative Methods, London: Sage.

Pawson, R. (2004) Mentoring Relationships: An Explanatory Review (Working Paper 21), Leeds: University of Leeds.

Pollack, S. (2004) 'Anti-oppressive social work practice with women in prison: discursive reconstructions and alternative practice', British Journal of Social Work, 34(5), 693-707.

Presdee, M. (2000) Cultural Criminology and the Carnival of Crime, London: Routledge. Rubin, A. and Babbie, E.R. (2012) Essential Research Methods, 2nd edn, Belmont, CA.: Cengage Learning.

Rumgay, J. (2004) 'Scripts for safer survival: pathways out of female crime', Howard Journal, 43, 405-19.

Sibley, D. (1995) Geographies of Exclusion, London: Routledge.

Spalek, B. (2008) Communities, Identities and Crime, Bristol: Policy Press.

Spivak, G.C. (1988) 'Can the subaltern speak?', in: C. Nelson and L. Grossberg (Eds.), Marxism and the Interpretation of Culture, Urbana, IL.: University of Illinois Press.

Stanley, L. and Wise, S. (1993) Breaking Out Again: Feminist Ontology and Epistemology, London: Routledge.

Tomczak, P.J. (2014) 'The penal voluntary sector in England and Wales: beyond neoliberalism?', Criminology \& Criminal Justice, 14(4), 470-86. 
Triangle Consulting Social Enterprise (2018) Outcomes Star. Available at: http://www.outcomesstar.org.uk (accessed 1 July 2018).

Tsui, M.S. (2004) Social Work Supervision: Contexts and Concepts, London: Sage.

Tyler, D.I. (2013) Revolting Subjects: Social Abjection and Resistance in Neoliberal Britain, London: Zed Books.

Vice, S. (1997) Introducing Bakhtin, Manchester: Manchester University Press. 